\title{
Kinetics of lead interaction with human erythrocytes
}

\author{
D. BARLTROP \\ M.D., F.R.C.P.
}

\author{
A. M. SMITH* \\ Ph.D.
}

\section{Paediatric Unit, St Mary's Hospital Medical School, London}

\begin{abstract}
Summary
The kinetics of the interaction of lead with human erythrocytes has been investigated in vitro by means of tracer studies with ${ }^{203} \mathrm{~Pb}$. The elution characteristics of lead from erythrocytes in contact with EDTA suggest the existence of two binding sites differing in their affinity for lead. The findings are consistent with the existence of two compartments for lead binding in the cell, and a model system based on this concept is proposed.
\end{abstract}

\section{Introduction}

Divalent inorganic lead ions are known to be associated with the erythrocyte rather than the plasma fraction of human blood (Clarkson and Kench, 1958). The significance of the lead concentration that occurs in the erythrocytes as a consequence of normal exposures has not been established and although the anaemia of plumbism has been attributed to impaired haemoglobin synthesis and decreased red cell life (Waldron, 1964), the mechanisms underlying these changes remains uncertain. It has been postulated that the cell membrane is the principal site for lead binding (Aub et al., 1925) but recent work with red cell haemolysates has shown that haemoglobin has a greater affinity for lead than erythrocyte stroma or membrane material (Barltrop and Smith, 1971). Chelating agents such as calcium disodium EDTA are commonly used in the treatment of lead poisoning and are thought to enhance the removal of lead from the soft tissues although it has been reported that some chelated lead is skeletal in origin (Hammond, Aronson, and Olson, 1967). There are, however, inconsistencies in the in vivo response so that the blood lead concentration is not always reduced to normal values by chelation therapy and may increase after the cessation of treatment. Studies with erythrocytes containing lead added in vitro have shown that little lead is removed by EDTA in contacts of short duration (Passow, Rothstein and Clarkson, 1961) and there is evidence that neither EDTA nor the lead-EDTA complex enters the red cell (Barltrop and Smith,

\footnotetext{
* Present address: Department of Employment, Baynard House, Chepstow Place, London.
}

1972). The apparent response to chelating agents in the treatment of clinical plumbism cannot therefore be explained in terms of the observed interaction of lead with erythrocytes in vitro. This paper reports kinetic studies which have been designed to explore the existance of erythrocyte binding sites for lead other than haemoglobin.

\section{Materials and methods}

Human whole blood was obtained by venepuncture and collected into lithium-heparin tubes. Stable lead solutions were prepared from $\mathbf{P b C l}_{2}$ dissolved in $0.9 \%$ sodium chloride and labelled with ${ }^{203} \mathrm{PbCl}_{8}$ in saline. Addition of the prepared lead solution was made to blood to give a final concentration of $5 \AA$ $\mu \mathrm{g} \mathrm{Pb} / 100 \mathrm{ml}$. CaNa ${ }_{2}$ EDTA solution in saline was added to blood to give a final concentration of 10 $\mathrm{mol} / \mathrm{l}$. Blood containing added lead was mixed contin uously in stoppered syringes on a rotary mixer and sampled at intervals. The aliquots thus obtained were centrifuged at $2500 \mathrm{rpm}$. and the distribution of added lead determined in aliquots of plasma and cells by counting at the photo peak for ${ }^{203} \mathrm{~Pb}(0.279 \mathrm{MeV})$ with a Hewlett-Packard Auto Gamma Spectrometer. Packed cell volumes were determined by means of a Hawksley microhaematocrit centrifuge. The precision of replicate experiments was such that the erythrocyte lead content could be determined to $\pm 1 \%$

\section{Results}

The uptake of lead by erythrocytes from saline was rapid at ambient temperatures and under the experimental conditions $97 \%$ of the added lead was associated with the cell fraction within $15 \mathrm{~min}$. The rate of lead uptake was decreased by cooling so that at $4^{\circ} \mathrm{C}$ the reaction was complete $30 \mathrm{~min}$ after initial contact (Fig. 1). The erythrocytes showed a marked affinity for lead and could accommodate concentrations greatly in excess of those encountered in clinical lead poisoning. Similar uptake characteristics were observed for lead at low concentrations added to plasma, however, at values exceeding 200 $\mu \mathrm{g} \mathrm{Pb} / 100 \mathrm{ml}$ blood an increasing proportion of lead remained in the plasma fraction which appeared to 


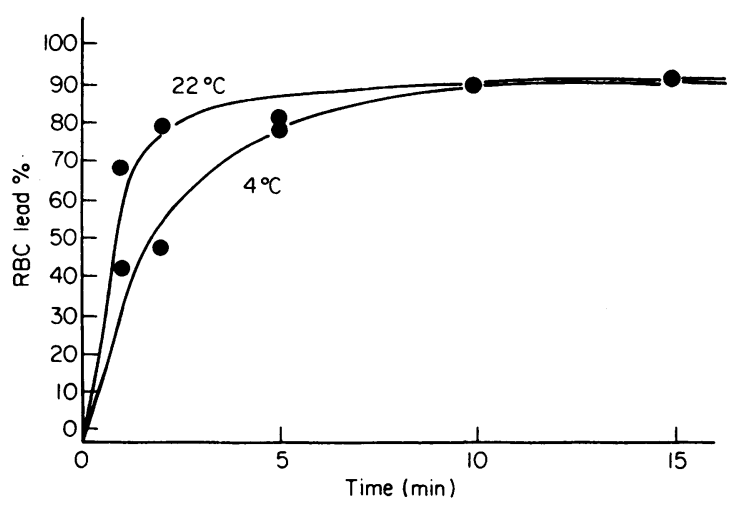

Fig. 1. The uptake of lead by erythrocytes from plasma at $22^{\circ} \mathrm{C}$ and $4^{\circ} \mathrm{C}$. Final concentration of lead, $50 \mu \mathrm{g} /$ $100 \mathrm{ml}$.

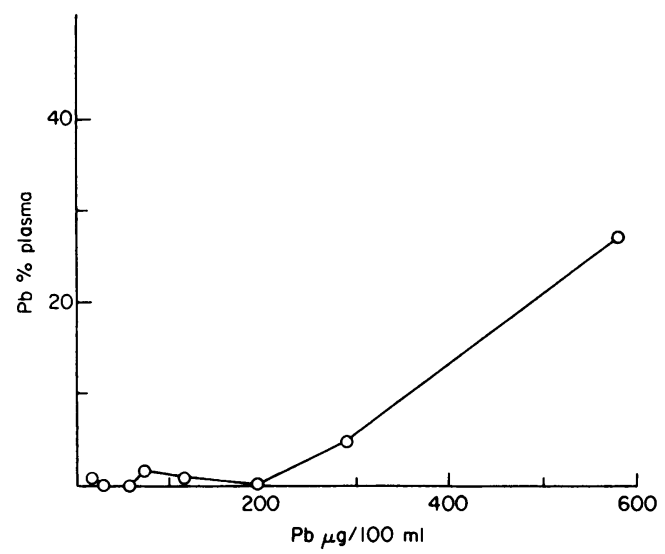

Fig. 2. Residual lead in plasma after contact with erythrocytes as a function of initial plasma lead concentration. Haematocrit $45 \%$.

be inaccessible to the erythrocytes (Fig. 2). This critical value is likely to have been exceeded in studies involving the intravenous administration of lead solutions owing to the local 'bolus' effect.

Initial investigations were designed to explore the kinetics of uptake by arresting the entry of lead into the cell by serial additions of EDTA to the system. Using this technique it was found that some lead escaped from the cells after initial entry thus invalidating this approach. Kinetic studies were therefore limited to the egress of lead from previously treated cells using the same technique of trapping with EDTA in the plasma phase.

Erythrocytes exposed to lead for $15 \mathrm{~min}$ gave a biphasic elution curve suggesting the existence of two binding sites differing in their affinity for lead. It would be expected therefore that with the lapse of time after initial contact with lead there would be progressive transfer from the weakly to firmly bound states. This hypothesis was tested by studying the elution characteristics of lead from cells after varying intervals of contact with the metal. Each study was controlled with cells maintained under identical conditions but to which lead had been added only $15 \mathrm{~min}$ before contact with EDTA. The findings indicated that the lead elution curves for the red cells altered with time such that recently added lead was more easily recovered (Figs 3 and 4).

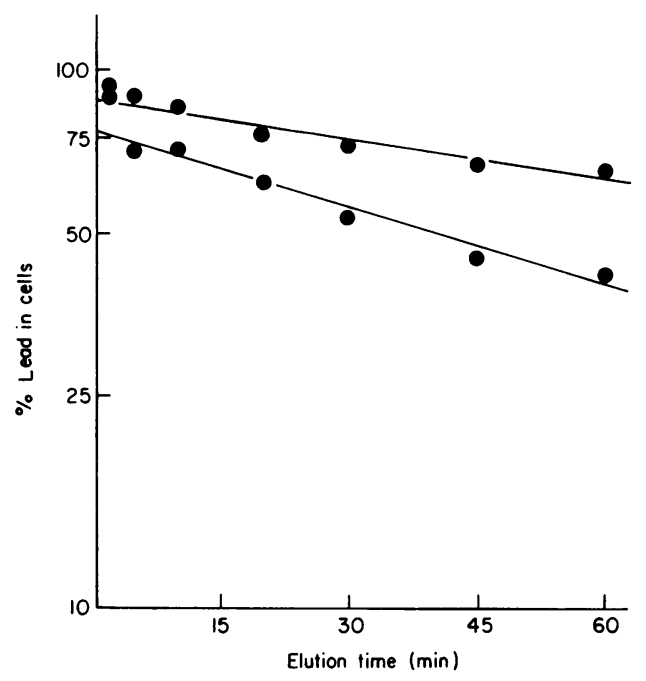

Fig. 3. Effect of duration of contact with lead on the rate of elution from erythrocytes by EDTA $10^{-4} \mathrm{~mol} / \mathrm{l}$. Cells $6 \mathrm{hr}$ in vitro at $22^{\circ} \mathrm{C}$. Time exposed to lead $6 \mathrm{hr}$ (top line) and $15 \mathrm{~min}$ (bottom line).

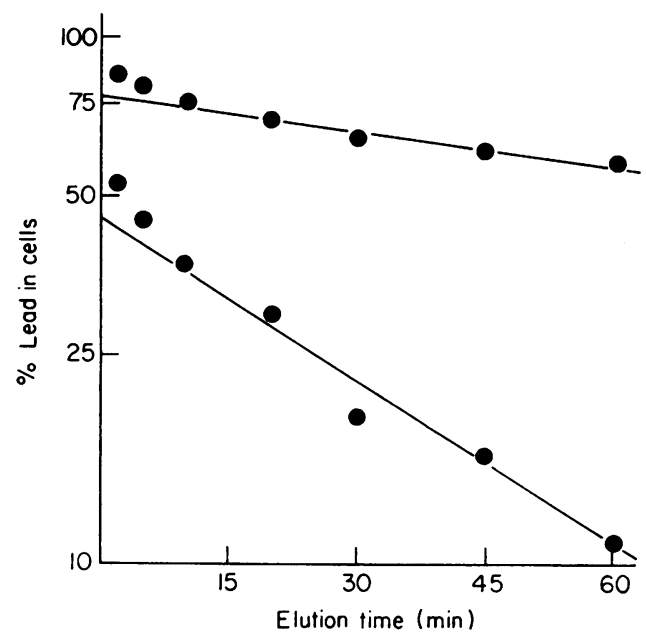

FIG. 4. Effect of duration of contact with lead on the rate of elution from erythrocytes by EDTA $10^{-4} \mathrm{~mol} / \mathrm{l}$. Cells $24 \mathrm{hr}$ in vitro at $22^{\circ} \mathrm{C}$. Time exposed to lead $24 \mathrm{hr}$ (top line) and $15 \mathrm{~min}$ (bottom line). 
It appeared, therefore, that two variables (elution time and in vitro time) determined the residual concentration of lead in the erythrocytes of the short contact system and their interrelationship is illustrated by means of a three dimensional display (Fig. 5). By contrast, lead contacts of long duration gave elution curves which were essentially similar for contact periods of $1.5-18 \mathrm{hr}$ although a slight increase in elution rate was observed after $24 \mathrm{hr}$ (Fig. 6). Inspection of the data in Figs 5 and 6

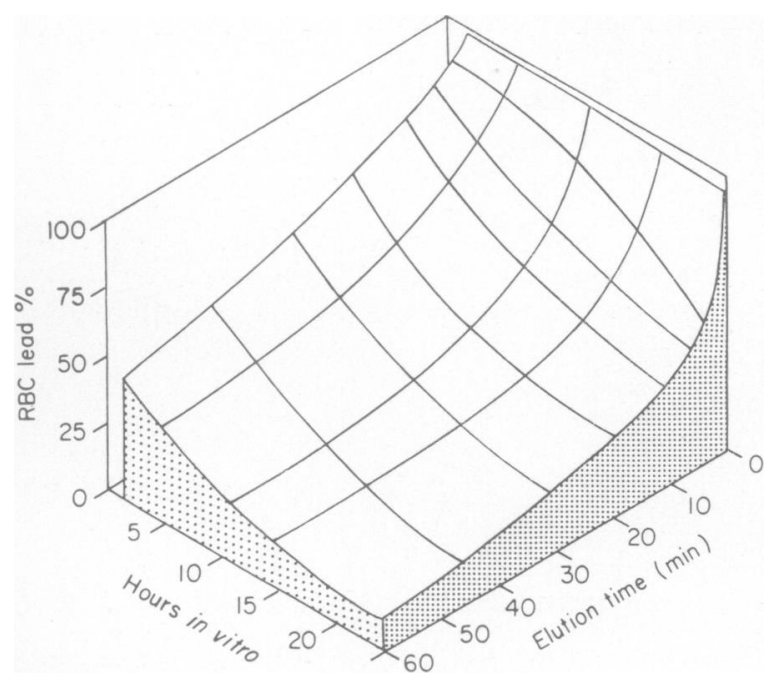

Fig. 5. Three dimensional display relating residual erythrocyte lead to time of cells in vitro and duration of elution by EDTA $10^{-4} \mathrm{~mol} / \mathrm{l}$. Cells in contact with lead 15 min pre-elution.

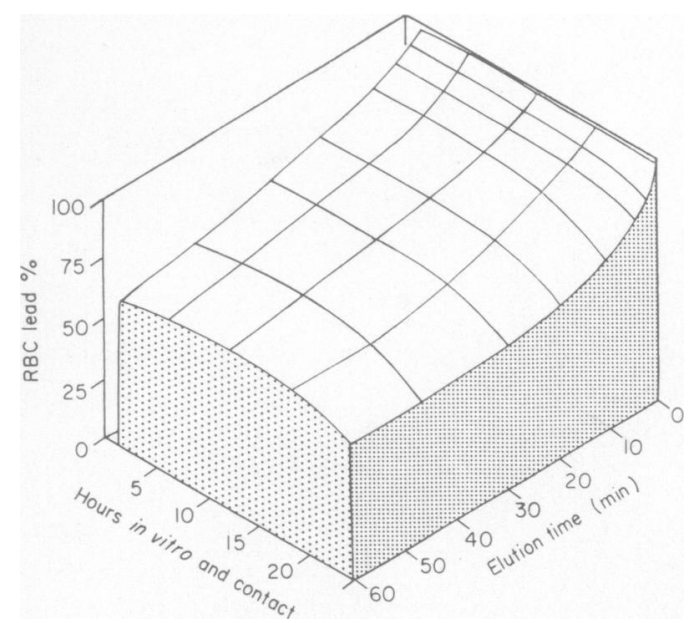

FIG. 6. Three dimensional display relating residual erythrocyte lead to time of cells in vitro and duration of elution by EDTA $10^{-4} \mathrm{~mol} / \mathrm{l}$. Cells in contact with lead throughout in vitro time. showed that the two planes tended to approximate at short in vitro times but this could not be explored experimentally because of the required interval of $15 \mathrm{~min}$ for completion of lead uptake from plasma.

Extrapolation of the data for both long and short contact systems to zero in vitro time (To) gave similar plots which did not differ significantly $(P=>0.05)$ and were linear after the first $10 \mathrm{~min}$. The intercept of the To plots on the ordinate $(92 \%)$ was less than the total erythrocyte lead content $(97 \%)$. This discrepancy, although small, could not be attributed to experimental error and is consistent with the existence of a second compartment in which $\mathrm{Pb}$ is less firmly bound.

The studies were repeated at $4^{\circ} \mathrm{C}$ to inhibit the metabolic activities of the cell at room temperature.

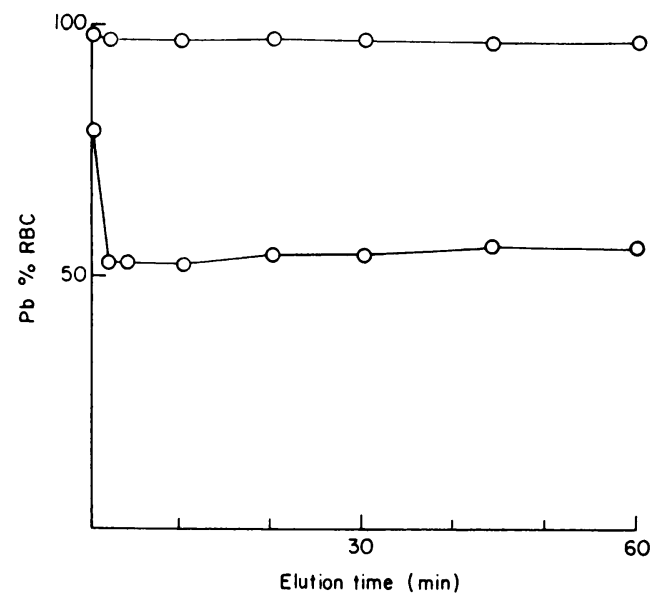

FIG. 7. Effect of duration of contact with lead on the rate of elution from erythrocytes by EDTA $10^{-4} \mathrm{~mol} / \mathrm{l}$. Cells in vitro $5 \mathrm{hr}$ at $4^{\circ} \mathrm{C}$. Contact time with lead $5 \mathrm{hr}$ (top line) and $15 \mathrm{~min}$ (bottom line).

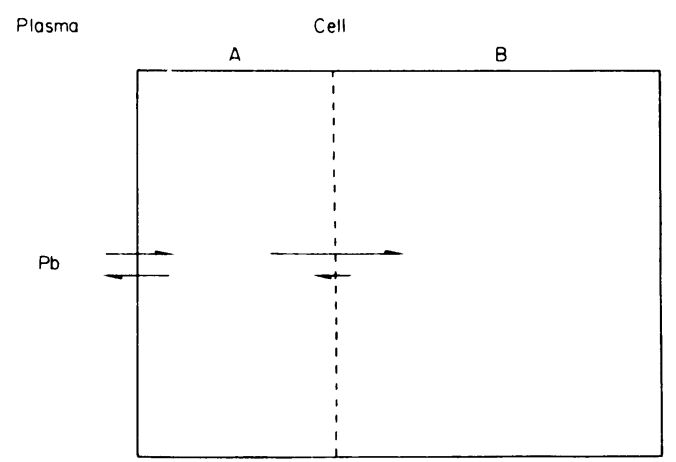

FIG. 8. Model system representing the interaction of lead with the erythrocyte. A and B represent compartments in which lead is bound loosely and firmly respectively. 
A marked increase in the availability of lead was noted for the short contact system such that $30 \%$ of the added lead remained available for elution within 2 min of contact with EDTA and no further loss could be demonstrated with increasing elution time. By contrast, lead in the long contact system remained unavailable to EDTA (Fig. 7). A model based on the hypothesis of a double compartment system can be represented diagrammatically (Fig. 8).

\section{Discussion}

The elution curves observed with EDTA suggest that the erythrocyte lead is not as firmly bound as was previously thought. The rate of removal of lead from the cells is greater than the previously published in vivo data. Castellino and Aloj (1965) showed that the biological half-life of lead in erythrocytes in the presence of EDTA in vivo is in the order of $110 \mathrm{hr}$, whereas the present studies suggest a value of 120 min. However, the in vivo situation is complicated by redistribution and equilibration between the tissues.

The data presented appear to support the existence of a second erythrocyte-associated compartment for lead binding, but do not provide evidence of its nature or site. The findings could equally well be explained by a primary combination of lead at the red cell surface with subsequent transfer through the membrane to combine with haemoglobin. Alternatively, they could represent binding to intracellular non-haemoglobin fractions preceding subsequent redistribution. The latter view is supported by the uptake and elution curves at $4{ }^{\circ} \mathrm{C}$ in which recently transferred lead remains more readily available to EDTA than in comparable studies at room temperature. The known characteristics of the leadhaemoglobin system are consistent with a reversible reaction in favour of complex formation which will thus be related to the duration of contact with lead. Cooling would tend to diminish dissociation so that complexed lead would be less available for elution by EDTA than at room temperature. It would appear, therefore, that the lead-haemoglobin complex is not directly accessible to EDTA and is situated in a second compartment.

It is suggested that compartment A binds lead weakly while in B the lead is more firmly bound with the equilibrium in favour of the lead-haemoglobin complex. Transfer from the plasma to compartment $A$ is little influenced by temperature whereas further transfer is critically temperature-dependent. Plasma lead is in equilibrium with compartment $\mathbf{A}$ and receives lead from $B$ only under conditions favouring dissociation of the lead-haemoglobin complex with intermediate binding in compartment $\mathrm{A}$.

An alternative explanation might be that the weakly bound component is represented by the plasma protein 'shell' at the erythrocyte membrane surface and that compartment $B$ is represented by the total erythrocyte contents. This would require the concept of free circulation of haemoglobin within the cell to allow transport of newly formed lead haemoglobin complex from the inner surface of the erythrocyte membrane. However, this would seem to be unlikely in view of the available evidence concerning the internal tructure of the erythrocyte (Perutz, 1948).

\section{Acknowledgments}

D.B. was a Wellcome Senior Fellow in Clinical Science. ${ }^{203} \mathrm{~Pb}$ was supplied by the M.R.C. Cyclotron Unit, Hammersmith.

\section{References}

Aub, J.A., Fairhall, L.T., Minot, A.S. \& Reznikoff, P (1926) Lead Poisoning, Williams and Wilkins, Baltimore

BARLTROP, D. \& SMITH, A.M. (1971) Interaction of lead witt? erythrocytes. Experientia, $27,92$.

Barltrop, D. \& SMITH, A.M. (1972) Lead binding to human haemoglobin, Experimentia, 28, 76.

Castellino, N. \& Aloj, S. (1965) Effects of calcium sodium ethylenediaminetetraacetate on the kinetics of distribution and excretion of lead in the rat. British Journal of Industrial Medicine, 22, 172.

Clarkson, T.W. \& Kench, J.E. (1958) Uptake of lead by human erythrocytes in vitro. Biochemical Journal, 69, 432.

Hammond, P.B., Aronson, A.L. \& Olson, W.C. (1967) The mechanism of mobilization of lead by ethylenediaminetetraacetate. Journal of Pharmacology and Experimental Therapeutics, 157, 196.

Passow, H., Rothstein, A. \& Clarkson, T.W. (1961) The general pharmocology of heavy metals. Pharmacology, 13, 185.

Perutz, M.F. (1948) Submicroscopic structure of the red cell, Nature, 161, 204.

WALDRON, H.A. (1964) The effect of lead on the fragility of the red cell incubated in vitro. Journal of Clinical Patho$\log y, 17,405$. 